\title{
Synthesis of carbon nanotube-carbon nanosphere on the CF surface by CVD
}

\begin{abstract}
In the current work, the synthesis of carbon nanotubes (CNTs) and carbon nanospheres (CNS's) has been investigated by applying the chemical vapor deposition method in a onestep sample preparation. In this method, iron nitrate non-hydrate $\left(\mathrm{Fe}\left(\mathrm{NO}_{3}\right)_{3} \cdot 9 \mathrm{H}_{2} \mathrm{O}\right)$ and acetylene $\left(\mathrm{C}_{2} \mathrm{H}_{2}\right)$ have been used as the catalyst source and carbon source, respectively, to grow CNT directly on the CF surface at $700^{\circ} \mathrm{C}$ and then CNS's were synthesized on the CNT layers at $900^{\circ} \mathrm{C}$ under a $250 \mathrm{sccm}$ gas flow rate $\left(40 \% \mathrm{~N}_{2}, 40 \% \mathrm{H}_{2}, 20 \% \mathrm{C}_{2} \mathrm{H}_{2}\right)$. According to the SEM and TEM micrographs from the resultant carbon nanoparticles, the diameters of the CNTs and CNS's have been estimated about 30-50nm and 300-400nm, respectively.
\end{abstract}

Keyword: Carbon fiber; Carbon nanosphere; Carbon nanotube; Chemical vapor deposition 